\title{
Observações sobre a recepção de Nietzsche em Portugal: passando por Pessoa até finais da década de noventa do século XX
}

\author{
António Marques*
}

\begin{abstract}
Resumo: Este artigo procura analisar a recepção da filosofia de Nietzsche em Portugal. Percorrendo um amplo espectro, visa a apontar as fortes marcas do pensamento nietzschiano na cultura portuguesa.

Palavras-chave: Nietzsche - Pessoa - recepção - Portugal
\end{abstract}

Por "recepção" entendemos aqui a forma como uma dada cultura, neste caso a portuguesa, a sua comunidade filosófica e não só, se apropria de um autor e da sua obra. Por outro lado pretende-se obter alguma luz sobre o modo como o próprio processo de recepção alterou ou influenciou aspectos importantes dessa cultura. Por isso mesmo vamos limitar-nos a uma avaliação retrospectiva daqueles momentos que devem considerar-se momentos chave na recepção de Nietzsche na espaço cultural e filosófico português, descurando assim obras e autores mais recentes do presente século. As contribuições mais próximas ou muito recentemente produzidas, encontram-se sobretudo sob a forma de teses de doutoramento no meio académico e merecem um estudo diferenciado.

\footnotetext{
* Professor da Universidade Nova de Lisboa, Lisboa, Portugal. E-mail: marquesantonio@ gmail.com.
} 
É possível dizer-se que em Portugal a primeira recepção de Nietzsche se fez sobretudo através da literatura, aliás como aconteceu com muitos outros autores e correntes filosóficas. Esse facto não nos deve admirar, pois que não será exagerado afirmar, de certo modo como hipótese que careceria de outro tipo de demonstração, que a cultura portuguesa, quando se exprimiu filosoficamente, o fez predominantemente através das expressões literárias que cada época configurou. Desde o neo-platonismo renascentista, sempre presente de uma forma consistente e explícita em Camões, até ao heideggerianismo, difuso e com raízes na poética de um Hölderlin, na obra daquele que é por muitos considerado o maior poeta português da segunda metade do século XX, Vitorino Nemésio, sempre a cultura portuguesa escolheu uma forma literária para exprimir ideias filosóficas. Não nos parece que seja uma característica única da cultura portuguesa e é provável que aqui sejamos acompanhados por muitas outras que, como ela, não participaram na vanguarda do progresso científico e tecnológico da modernidade europeia. Existe, como é sabido, uma correlação entre produção filosófica e desenvolvimento científico que não cabe aqui explorar, mas que explicará em parte aquela característica. Aliás, apenas por curiosidade, note-se como a produção filosófica originalmente portuguesa, que teve verdadeiro impacto europeu, foi, na segunda metade do século XVI, o chamado Cursus Conimbricensis, um conjunto de comentários do neo-tomismo tardio a obras de Aristóteles, produzido na Universidade de Coimbra.

Interessante será traçar um paralelismo com o que aconteceu no País vizinho. Embora a situação de Espanha não seja a este respeito muito diferente, não tivémos para Nietzsche, um Ortega y Gasset, em cuja La Rebelion de las Masas (1930) são reconhecíveis elementos do vitalismo filosófico, de Darwin, Bergson e certamente de Nietzsche. O que nessa obra Ortega filosoficamente expõe é o perigo do igualitarismo, o apagamento das categorias da diferença e da excelência, em que as sociedades modernas incorrem. As massas tendem a ocupar o espaço público, num movimento de 
rebelião contra as elites, porque nelas passou a dominar o impulso para a mediocridade e a fraqueza da pequena segurança. Assim são as forças inferiores que se sobrepõem às superiores e é a própria vida que se degrada numa mera vontade de viver como o homem medíocre. Reconhecemos pois na obra de 1930 de Ortega os grandes tópicos de Nietzsche: a vida como algo que deve ser mais do que uma mera vontade de viver, a crítica ao homem moderno como homem do rebanho ou a redução da cultura à figura do último homem e consequente transformação niilista.

Apenas se refere aqui Ortega para sublinhar a ideia que em Portugal não houve um seu correspondente, que nos permita falar numa determinada recepção filosófica da filosofia de Nietzsche. De facto, para a geração de literatos e ensaístas que dominaram a cena intelectual portuguesa nas primeiras duas ou três décadas deste século, o filósofo que contava era Bergson e o conceito que enalteceram foi o de élan vital, no qual encontraram inspiração para o renascimento de uma cultura nacional, em oposição ao cientismo. Este foi o nome que deram à desumanização da vida por uma certa cultura industrializada de massas, ao empobrecimento espiritual que se traduzia no desaparecimento da memória colectiva. Em Portugal, curiosamente, os intelectuais seguidores de Bergson (cuja influência ainda se faz sentir em Portugal até muito mais tarde com José Marinho) eram republicanos convictos e o movimento a que se chamou a Renascença portuguesa, sendo anti-progresso científico e anti-positivista propunha-se ser uma força renovadora da sociedade portuguesa, atenta às questões sociais de uma sociedade arcaica e decadente. Pelo menos foi assim que literatos e ensaístas como Teixeira de Pascoaes ou Leonardo Coimbra compreenderam o seu papel de vanguarda nas duas primeiras décadas do século. Alguns historiadores das ideias notarão no entanto que este movimento facilmente foi absorvido pelas correntes mais conservadoras do pensamento católico, no quadro do Estado implantado por Salazar, a partir de princípios dos anos 30. Armados de bergsonismo e assumindo a subordinação da razão à intuição, lutaram contra 
Marques, A.

outro ramo da inteligência portuguesa que entretanto se formara mais próxima de um racionalismo aristocrático. Este é formado por ensaístas como Raul Proença e sobretudo António Sérgio, sem dúvida o promotor incansável e diríamos heróico, no contexto português deste século, de um racionalismo de síntese entre o empirismo anglo-saxónico e o kantismo. Enquanto movimento intelectual, este bergsonismo português não gerou uma escola consistente, com um perfil ideológico definido ou com prolongamentos académicos duradouros. Na verdade o que dele derivou foi um conjunto de ramificações bizarras do culto do que, até aos nossos dias, se chamou o saudosismo português com características mais ou menos místicas, mais ou menos nacionalistas. Não é pois este núcleo de literatos e ensaístas na linha de Bergson que acolhe ideias ou tópicos especificamente nietzschianos.

Penso que se os quisermos encontrar, teremos de olhar para o poeta português mais multifacetado e influente da primeira metade do século XX, cuja poética assentou na criação de personagens entre si muito diferentes e criadoras de um universo poético singular. Refiro-me a Fernando Pessoa e aos seus heterónimos. A relação de Pessoa ele próprio com o filósofo Nietzsche é explicitamente conflituosa e chega mesmo a ver o filósofo da vontade de poder nos seus antípodas. É que Pessoa considera-se herdeiro de um paganismo clássico, o qual ele propõe renovar e, desse ponto de vista, entende Nietzsche como o arauto de um outro paganismo, igualmente anti-cristão, mas nórdico, violento e dominador. $\mathrm{O}$ neopaganismo de Pessoa, pelo contrário, restaurará a objectividade e a naturalidade do real, rejeitando como Nietzsche qualquer transcendência de teor neo-platónico, mas rejeita igualmente a figura de um Übermensch que a seus olhos seria sempre uma entidade não natural e inumana. Paralelamente discorda da interpretação que Nietzsche faz da figura de Diónisos: “... não era em nome do paganismo greco-romano que ele erguia o seu grito, embora o cresse; era em nome do paganismo nórdico dos seus maiores. E aquele Diónisos, que contrapõe a Apolo, nada tem a ver com a Grécia. 
É um Baco alemão"1. Um estudo sistemático sobre as relações entre a poética de Pessoa, ou entre a poética de cada uma das suas personagens, e Nietzsche nunca foi empreendida, com nosso conhecimento, apesar de geralmente se aceitar, quase que intuitivamente, na sua obra a presença diversa do filósofo. É assim que um artigo de Eduardo Lourenço (ver literatura utlizada), representa uma das primeiras, senão a primeira análise filosófica consistente da relação entre os dois autores.

Defende Lourenço que se pode considerar dois níveis de nietzshianismo na obra de Pessoa. Um encontramo-la na poesia de um heterónimo, Álvaro de Campos, a consciência futurista por excelência, que exalta a vida e o que esta tem de risco e imprevisibilidade. $\mathrm{O}$ que é essencial nessa poesia é o simbolismo da viagem marítima e tudo o que a esta se liga de descoberta de outros mundos, com a correspondente experiência do perigo e da exaltação dos sentidos. Se há um sentido da vida, este deve procurar-se nessas experiências de uma certa alienação ou perda de si. O outro nível da presença de Nietzsche ou de uma visão nietzschiana em Pessoa, encontramo-la segundo Lourenço, noutro heterónimo, Alberto Caeiro, o poeta afirmativo por excelência, vivendo até ao limite numa relação íntima com a natureza e em cujos versos ecoa a ideia de um eterno retorno das coisas. Quanto ao primeiro defende Lourenço que a relação com Nietzsche será mais superficial e apresenta-a da seguinte forma: "É sob a máscara de Álvaro de Campos que Pessoa parece representar outros temas de ressonância nietzsheana como o da Vida como realidade última, intrinsecamente contraditória, mas exaltante, versão moderna da ideia de Heráclito da guerra-vida ou da vida-guerra, mãe de todas as coisas e pura energia. Álvaro de Campos parece mesmo ter sido inventado com a mediação formal de Walt Whitman, para encarnar uma visão, senão dionisíaca no sentido específico de

1 PESSOA, F. Páginas Íntimas e de Auto-Interpretação. Ed. Ática: Lisboa, s/d., p. 236. 
Marques, A.

Nietzsche, pelo menos activa, frenética, manifestação de realidades contraditórias e fonte de acções indiferentes ao Bem e ao $\mathrm{Mal}$ segundo a moral convencional. A sua poética da indiferença moral, exaltadora de um certo jogo da Vontade de Poder que não exclui a apologia de uma crueldade e de uma violência ostensivamete anticristã ecoa a versão mais popular do 'pensamento' de Nietzsche ou cabe na lógica profunda da sua visão (...) Na realidade, o poeta da Ode Triunfal e da Ode Marítima oscila constantemente entre a visão cruel de Nietzsche e o fraternalismo espiritualizante de Walt Withman. Assim, às grandes exaltações da vida bárbara, livre, aquém ou além do Bem e do Mal, amorais no sentido de Nietzsche, a evocação dos actos in-humanos do eu-pirata da Ode Marítima que deviam conferir ao poema o seu perfil de epopeia da transgressão moderna, sucedem reflexos e arrependimentos na mais velha linha da culpabilidade cristã".

É pois só uma parte de Nietzsche, talvez a mais superficial e popular, que aparece transfigurada na poesia do heterónomo Álvaro de Campos. Por outro lado, como se vê, a existência neste universo poético de elementos aparentados com a visão panteísta- fratrernalista de Withman retira certamente a Álvaro de Campos o estatuto de poeta nietzsheano por excelência. Aliás, acrescentaremos nós, o aspecto mais obviamente nietzshiano que Pessoa apresentará através dessa personagem, insere-se numa linha literária que remonta pelo menos a Jack London e tem nos nossos dias expressões diversas, entre as quais uma certa literatura do excesso e do mal como é a de George Bataille. Será de reconhecer a filiação de toda essa linha complexa na obra de Nietzsche? A nossa inclinação será a de reconhecer que de facto que ele é uma das inspirações mais profundas para todos estes autores e que a compreensão das suas obras só ganha quando as lemos dentro

2 LOURENÇO, E. Nietzsche e Pessoa. In: MARQUES, A. (org.). Nietzsche: Cem Anos Após o Projecto "Vontade de Poder- Transmutação de Todos os Valores". Vega: Lisboa, 1988, p. 257-8.

18 | cadernos Nietzsche 31, 2012 
de um quadro de referências construído pelo filósofo. Porém, ainda no caso de Pessoa, e segundo a interpretação de Lourenço, a presença de Nietzsche far-se-á talvez sentir mais amplamente noutro heterónimo, Alberto Caeiro, em cuja poesia é iniludível um conjunto de ideias chave do filósofo: o sim à vida e a aceitação sem remorsos do momento presente, a temporalidade como um ciclo que reactualiza tudo aquilo que é essencialmente humano. É no universo da personagem Caeiro que, nas palavras de Lourenço "nós encontramos uma visão do mundo mais sintonizada com uma das leituras possíveis de Nietzsche, se nós reduzimos o essencial dessa visão, como Heidegger nos autoriza, ao pensamento do Eterno Retorno. Se deixarmos de lado as leituras parapositivistas da concepção de Nietzsche e nos ativermos à interpretação do pensamento supremo, na esteira de Heidegger e de Deleuze, como retorno do mesmo, quer dizer como metáfora da aceitação e da afirmação da realidade eterna do presente na sua face eternamente contraditória, a atitude do Guardador de Rebanhos, imaginado por Pessoa, não está muito afastada da de Zaratustra e do seu sim sem reservas à vida"3.

Não vamos aprofundar aqui a dificuldade desta interpretação, de que aliás Lourenço se dá conta, ao notar como este universo poético, se é verdade que se pode aproximar de certos conceitos de Nietzsche, não é menos próximo da experiência de um Francisco de Assis, afinal a quinta essência de uma ideia de cristianismo. Sendo assim, deve concluir-se que na poesia de Pessoa, alguns tópicos nietzschianos convivem com outros nos antípodas da filosofia de Nietzsche. A nosso ver seria correcto dizer que o seu nietzscheanismo se encontra, não tanto nos conteúdos, mas sobretudo na forma, isto é, na própria construção dos heterónimos, na possibilidade da vivência por dentro de personagens que, por assim dizer, substituem um eu enquanto entidade una que se vê a si

3 Idem, p. 259. 
Marques, A.

próprio como centro criador de sentido. Aquele eu que no final da vida lúcida do filósofo era afinal a experiência de todos os nomes da História, uma espécie de faculdade singular de perspectivar a partir do interior de personagens diferentes. Esse eu múltiplo, de tal forma que não é possível dizer-se o que estará "por detrás" deles, vai ser a novidade da poética de Pessoa. É assim este que pode escrever, numa linha pensamento certamente próxima de uma certa crítica de Nietzsche à ideia de um eu substancial, que o "poeta exprimir-se-á como uma multiplicidade de personagens, unificadas, não já pelo temperamento e o estilo, pois que o temperamento está substituído pela imaginação, e o sentimento pela inteligência, mas tão somente pelo simples estilo"4.

Até muito recentemente a recepção relevante de Nietzsche é pois de tipo literário e não será demais sublinhar a ambiguidade da presença do filósofo na poesia de Pessoa, presença aliás jamais explicitamente assumida. Na verdade, para além desse tipo de acolhimento, não se pode afirmar que durante várias décadas tenha havido de uma forma consistente outro tipo de recepção de Nietzsche. Para isso teria sido necessário que na Universidade houvesse espaço para tal. Simplesmente os estudos filosóficos em Portugal, nos curricula universitários, sempre se dividiram entre a história das ideias ou da cultura e certo tipo de correntes fenomenológico-existencialistas de inspiração católica. Nietzsche não era pois filósofo que se enquadrasse nesse ambiente, certamente hostil à representação mais forte que então era feita do filósofo, isto é, o Anti-Cristo iconoclasta por excelência, senão mesmo o precursor de ideologias racistas. Curiosamente, e à primeira vista paradoxalmente, nos anos cinquenta e sessenta, Nietzsche é o autor filosófico mais traduzido em Portugal, em circuitos que nada tinham a ver com a Universidade, ainda que as traduções, em grande parte, não cumprissem critérios de qualidade. Não será

4. LOURENÇO, E., op. cit, p.107.

20 | cadernos Nietzsche 31, 2012 
menos curioso verificar que são discípulos da corrente saudosista (que como se viu nasce nas primeiras décadas do século, juntando um certo bergsonismo a elementos nacionalistas), os quais nunca conquistaram posições universitárias durante o regime ditatorial, que assim mantiveram vivo o interesse por Nietzsche. Pode então dizer-se que sempre se leu Nietzsche em Portugal, nas décadas de 50 e 60, mas que apenas a partir do momento em que se tornou possível institucionalizar o seu estudo na Universidade, começaram os estudos nietzschianos verdadeiramente em Portugal. Na verdade só com o fim do antigo regime e a abertura dos curricula a novos autores, temas e metodologias, é que se pode dizer que teve início de uma forma consistente o estudo do filósofo. Algumas dissertações foram entretanto produzidas nos departamentos de filosofia e, nas cadeiras de filosofia contemporânea, Nietzsche começou a aparecer como autor obrigatório. Por outro lado, na disciplina de Filosofia do ensino secundário, Nietzsche é introduzido, ainda que como alínea de um capítulo sobre os valores morais. Ainda hoje, ou pelo menos até há bem pouco tempo, no último ano dos liceus, os alunos que escolhem Filosofia devem ler $O$ nascimento da tragédia. Devo ainda referir que parte da nova geração de intelectuais portugueses que se forma nos anos 70 em torno da influência do estruturalismo e neo-estruturalismo francês lê muito Nietzsche, um Nietzsche nesse caso muito filtrado pelas interpretações de Foucault e de Deleuze. Pode afirmar-se que, nesse período, se leu o filósofo, sem que ainda sobre ele se escrevesse. De qualquer modo foi uma década decisiva para que se consolidasse definitivamente uma imagem de Nietzsche nos antípodas, quer da imagem do filósofo que serve de instrumento a uma ideologia racista, quer daquela outra imagem cultivada pelos saudosistas.

Gostaríamos agora de assinalar alguns pontos de referência, trabalhos editados e linhas de investigação que possam transmitir uma ideia o mais clara possível dos estudos sobre a filosofia de Nietzsche, ocorridos em Portugal mais ou menos nos últimos quinze anos. Digo mais ou menos quinze anos, já que nos parece 
Marques, A.

um momento importante de visibilidade e relançamento da filosofia de Nietzsche em Portugal, o conjunto de textos de vários autores dedicados à interpretação da sua filosofia publicados em 1987, como resultado de um colóquio no Goethe Institut de Lisboa, sob o tema "Nietzsche: cem anos após o projecto vontade de podertransmutação de todos os valores (Wille zur Macht-Umwertung aller Werte)". Com excepção de um filósofo alemão, Volker Gerhardt, todos os ensaios apresentados foram de autores portugueses. Esse colóquio mostrou em primeiro lugar que já nessa altura existia em Portugal uma comunidade, ainda que pequena, de filósofos que eram capazes de trabalhar a filosofia de Nietzsche com razoavelmente altos padrões científicos e académicos. Confirmou ainda ao público que acorreu em grande número, que Nietzsche era um filósofo extremamente actual, uma chave essencial para compreendermos a nossa contemporaneidade e não apenas uma curiosidade da história do pensamento ocidental. Serviu ainda para retirar definitivamente Nietzsche do exclusivo círculo hermenêutico do neo-estruturalismo francês. Aí são apresentadas as relações sistemáticas entre Nietzshe e a tradição filosófica (os filósofos pré-socráticos, Espinosa, Kant, Hegel e Schopenhauer), leituras de uma filosofia da corporeidade (Philosophie der Leiblichkeit) em Kant e Nietzsche, do projecto de transmutação dos valores em torno dos conceitos fundantes (grundlegende Begriffe) de vontade de poder e de niilismo, interpretações das relações entre perspectivismo e pragmática, do lugar de Nietzsche na chamado hermenêutica pós-moderna e das relações entre o filósofo e Fernando Pessoa, a que já nos referimos. A edição de 1500 volumes das actas do colóquio, foi muito vendida e quase esgotou no prazo de ano e meio, o que demonstrou o interesse potencial em relação a Nietzsche do público português, aliás excedendo muito a comunidade filosófica propriamente dita. Nos últimos anos da década de oitenta consolidaram-se pois os estudos nietzschianos, várias teses foram apresentadas nos departamentos universitários de filosofia e não apenas aí. A partir de então a sua filosofia é definitivamente parte integrante dos curricula dos 
cursos não apenas universitários, como também do ensino liceal. Assegurou-se então talvez a condição básica para aquilo que de algum modo sempre faltou para o desenvolvimento dos estudos sobre Nietzsche: o seu reconhecimento como filósofo fundamental da tradição filosófica ocidental.

A partir daqui vou referir-me a algum material publicado e ao que é possível considerar como momentos significativos da recepção de Nietzsche em Portugal. Em 1994 é publicado por Fernando Belo um estudo exegético de grande minúcia sobre ensaio do jovem Nietzsche de 73 Acerca da verdade e da mentira no sentido extra-moral (Über Wahrheit und Lüge im aussermoralischen Sinne). A grelha de interpretação, utilizada por Belo, é inspirada no desconstrucionismo de Derrida. O texto de Nietzsche é analisado como uma estrutura complexa de imagens e metáforas que se organizam para evidenciar o facto do próprio conhecimento humano ser essencialmente imagem e metáfora. Na história da filosofia alguns autores já haviam dado relevância ao valor semiótico de todo e qualquer conhecimento, isto é, ao facto do conhecimento não ser separável da interpretação de signos, os quais são, por sua vez uma produção humana e constituem um sistema próprio, com regras internas. A novidade de Nietzsche consiste em explicar essa actividade semiótico-cognitiva como uma construção perspectivista de que o homem terá perdido precisamente a consciência da sua natureza perspectivista. Por assim dizer o homem, filósofo ou cientista, que ainda acha que a sua linguagem de conceitos lhe traz alguma verdade do mundo, esqueceu-se que a essa linguagem é uma teia de metáforas e imagens que nunca representou originalmente o mundo. Assim a ilimitada e imbricada rede de conceitos que a razão produz, para supostamente obter a verdade, em momento nenhum da história do homem representou fielmente as coisas singulares e intrinsecamente diferentes. Pelo contrário, o que a linguagem fez não foi senão uma contínua prática de dissimulação. A leitura de Belo deste texto admirável do jovem Nietzsche aproveita a crítica ao conceito de verdade e o papel desempenhado pela metáfora 
Marques, A.

como deslocação de sentido, para situar a obra como fundadora do pensar pós-moderno. É o que se significa nas últimas linhas deste ensaio, que teve a sua repercussão na fase final do debate em Portugal acerca do pensamento pós-moderno: "Se não há senão metáforas, se tudo é metáfora, a metáfora deixa de ser um 'conceito' interessante, abre lugar ao jogo das interpretações indefinidas, repetindo afirmações num deslocar constante que as desmultiplica, sem cessar, sem continuidade" . A interpretação pós-moderna de Nietzsche reaparece ainda noutros autores, no campo das ciências humanas, como por exemplo em ensaios diversos de J. Bragança de Miranda e é sempre a primazia do discurso sobre o real, da interpretação sobre a verdade, e da perspectiva sobre verdade racionalmente justificada que nesses textos emerge. Uma linha de avaliação diferente de Nietzsche tinha já sido por nós próprios apresentada num ensaio intitulado Sujeito e Perspectivismo, seguido de uma selecção de textos do filósofo sobre o tema perspectivismo. Em oposição às teses pós-modernas procurámos um outro sentido para o próprio conceito de perspectivismo, argumentando que ele não se encontrava afastado de uma tradição filosófica moderna e que é ainda um produto de uma racionalidade que reflecte criticamente sobre si mesma. Sobretudo as relações com Kant são aí valorizadas, no pressuposto que neste filósofo é sobretudo o uso (perspectivista) dos conceitos que está em causa, no quadro de uma racionalidade do como se. Passando ao lado de questões técnicas, uma mesma orientação fundamental aproximaria Nietzsche de um certo perspectivismo kantiano: o sentido que encontramos nas coisas ou naquilo a que nos opomos como nosso exterior, é sempre por nós introduzido e por isso nunca vem já dado. Este nosso ensaio apresentou pois um outro Nietzsche, não marginal à modernidade ocidental e de algum modo permaneceu como ponto de referência e alternativa às interpretações pós-modernas e pós-estruturalistas.

5 BELO, F. Leituras de Aristóteles e de Nietzsche. Fundação Gulbenkian: Lisboa, 1994, p. 291.

24 I cadernos Nietzsche 31, 2012 
Para além do debate sobre Nietzsche no quadro mais amplo do debate moderno/pós-moderno, característico dos anos 80, princípios dos anos 90, um outro tópico relevante na recente recepção da filosofia de Nietzsche em Portugal, pode dizer-se que foi a problemática da tragédia. Deve aqui entender-se o termo, não tanto como categoria literária, mas sim como categoria filosófica que articula entre si um conjunto de conceitos que Nietzsche utilizou na sua interpretação do homem contemporâneo. Em 95, na Fundação Gulbenkian decorreu um colóquio sobre a tragédia grega e o conceito do trágico em Nietzsche, cujas actas foram publicadas um ano mais tarde, sob o título As Bacantes e o nascimento da tragédia. Amplamente divulgado nos meios de informação, o colóquio, com 11 comunicações, foi um sucesso e o público acorreu em grande número. É interessante lembrar que no âmbito deste colóquio foi pela primeira vez encenada em Portugal, concretamente no belo anfiteatro ao ar livre da Fundação Gulbenkian, a tragédia de Eurípides, As Bacantes. Um outro momento importante dos estudos nietzschianos, ainda sob a égide do conceito de tragédia foi a publicação, em 97, de um conjunto de ensaios de Nuno Nabais intitulado Metafísica do trágico. Este conceito é tratado ao longo da obra de Nietzsche e não se concentra unicamente nos textos especificamente sobre a tragédia. Nabais apresenta a teoria trágica de Nietzsche em torno dos seguintes pontos: "os conceitos de indivíduo e de individualidade, as diferentes figuras da necessidade e da contingência, a relação entre ética estóica e a máxima trágica de Amor fati, o lugar da ideia de eterno retorno na evolução da obra de Nietzsche, as diferentes interpretações da experiência de culpa e a teoria do niilismo como nova compreensão trágica da existência"6. Trata-se pois de um estudo sistemático que propõe uma reavaliação

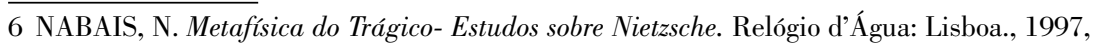
p. 13. 
Marques, A.

da rede conceptual fundamental que sustenta a obra de Nietzsche. Refira-se que este livro foi premiado com o prémio Pen Clube de Portugal para a melhor obra ensaística do ano.

Por último, e como que a fechar simbolicamente a década, outro momento relevante foi o da publicação em 1996- 1997, de sete volumes de obras escolhidas de Nietzsche pelo Círculos de Leitores, o maior clube de livros em Portugal. A edição, por nós coordenada, pretendeu dar ao público português novas traduções da maior parte das obras publicadas em vida do filósofo, traduções feitas com critérios académicos sólidos e acompanhadas de introduções filosoficamente credíveis, ainda que acessíveis a um público muito mais amplo do que o da comunidade de especialistas em Nietzsche. Recentemente tomámos conhecimento de um estudo sobre a recepção de Nietzsche na vida intelectual portuguesa de 1892 a 1939 da autoria de Américo Enes Monteiro, estudo extenso, cuidade e muito informarivo.

Este não é um panorama completo da recepção filosófica de Nietzsche em Portugal e muitas lacunas ficam por preencher. Basta referir as dissertações não publicadas que entretanto têm vindo a ser apresentadas nas universidades. Por outro lado, a presença de Nietzsche no ensaísmo e na literatura portugusa pós-Pessoa merece um estudo cuidado e sistemático que ainda não foi feito. Interessounos sobretudo desenhar grandes linhas filosófico-literárias que determinaram a recepção do filósofo e lançar uma ponte entre o filósofo alemão e o nosso autor mais original e complexo do século XX, o poeta/filósofo Fernando Pessoa.

\footnotetext{
Abstract: This article intends to analyze the reception of Nietzsche's philosophy in Portugal. Covering a wide spectrum, the article points out the strong markings of Nietzschean thought on Portuguese culture.
}

Keywords: Nietzsche - Pessoa - reception - Portugal

26 | cadernos Nietzsche 31, 2012 


\section{referências bibliográficas}

BELO, F. Leituras de Aristóteles e de Nietzsche. Fundação Gulbenkian: Lisboa, 1994.

MARQUES, A. (org.). Nietzsche: Cem Anos Após o Projecto "Vontade de PoderTransmutação de Todos os Valores". Vega: Lisboa, 1988.

. Sujeito e Perspectivismo. Dom Quixote: Lisboa, 1989.

MONTEIRO, A. E. A Recepção da Obra de Friedrich Nietzsche na Vida Intelectual Portuguesa. Lello Editores: Porto, 2000.

NABAIS, N. Metafísica do Trágico- Estudos sobre Nietzsche. Relógio d’Água: Lisboa., 1997.

NIETZSCHE, F. Obras Escolhidas. Círculo de Leitores: Lisboa, 1996-7, 7 v.

PESSOA, F. Páginas Íntimas e de Auto-Interpretação. Ed. Ática: Lisboa, s/d.

Artigo recebido em 17/06/2012.

Artigo aceito para publicação em 20/07/2012. 